\section{Performance of GDx and HRT in the Finnish Evidence- Based Guideline for Open-Angle Glaucoma}

LE Pablo ${ }^{1,2}$, JM Larrosa $^{1,2}$, V Polo $^{1,2}$, A Ferreras ${ }^{1,2}$, EG Alías ${ }^{1}$ and FM Honrubia ${ }^{1,2}$

\section{Abstract}

Aim To compare the performance of Heidelberg retina tomograph (HRT) and scanning laser polarimetry (GDx) with photographic evaluation of the optic nerve head (ONH) and retinal nerve fiber layer (RNFL) in the application of the Finnish Evidence-Based Guideline for Open-Angle Glaucoma.

Methods A total of 41 control participants and 312 patients referred for glaucoma evaluation were included in the study. All the participants underwent ophthalmic evaluation, $\mathrm{ONH}$ stereophotography, monochromatic RNFL photography, HRT, optical coherence tomography, and GDx evaluation. Participants were classified on the basis of stereophotographic or imaging device results based by applying the Finnish Guideline.

Results Agreement between the stereophotographic evaluation and that on the basis of the imaging devices was $52.9 \%$. Classification of patients with similar management advice on the basis of these evaluations had $56.4 \%$ agreement. The specificity of the Finnish guideline for detecting normal patients was $\mathbf{7 8 \%}$ (stereophotography) and $83 \%$ (imaging devices). Optic disc size interfered with the diagnosis in patients evaluated using the HRT3 glaucoma probability score. Structural changes were more frequently detected before functional changes.

Conclusion The Finnish Evidence-Based Guideline for Open-Angle Glaucoma is useful for classifying normal participants and patients with suspected glaucoma or glaucoma through either conventional stereophotographic evaluation of the neuroretinal structures or with the new imaging devices. Eye (2010) 24, 297-303 doi:10.1038/eye.2009.95; published online 1 May 2009

Keywords: glaucoma; diagnosis; evidence-based guidelines; HRT; OCT; GDx

\section{Introduction}

Glaucoma is a major cause of vision impairment characterized by structural changes of the optic nerve head $(\mathrm{ONH})$ and retinal nerve fiber layer (RNFL). These changes lead to visual field loss and eventually blindness. ${ }^{1,2}$

The primary goal of glaucoma treatment is to prevent further damage to these structures and to minimize the decline in eye function. Assessment of glaucomatous changes is dependent of the examination method and demands a high level of examiner experience. The introduction of imaging devices may decrease the reliance on the subjective interpretation of the observer. The performance of these tests, however, should be compared with stereophotographic evaluation of $\mathrm{ONH}$ and RNFL by trained observers, as recommended by recent clinical trials, such as the Advanced Glaucoma Intervention Study. ${ }^{3}$

Major scientific societies have presented recommendations for glaucoma management, for example, the European Glaucoma Society Guidelines, the American Academy of Ophthalmology Preferred Practice Patterns for Open-Angle Glaucoma, and the Finnish Evidence-Based Guideline for Open-Angle Glaucoma. ${ }^{4-6}$ The latter guideline is on the basis of evaluation of the ONH and RNFL and the recommendations for action are on the basis of very high quality studies. These guidelines are

\section{Department of Ophthalmology. Miguel Servet University Hospital, Instituto Aragonés de Ciencias de la Salud, Zaragoza, Spain \\ ${ }^{2}$ Department of Ophthalmology, University of Zaragoza, Zaragoza, Spain}

Correspondence: A Ferreras, Department of Ophthalmology,

Miguel Servet University Hospital, Isabel La Católica 1-3, Zaragoza 50009, Spain

Tel: + 34976765558 ;

Fax: + 34976566234 .

E-mail: aferreras@

msn.com

Received: 25 November 2008

Accepted in revised form: 26 March 2009 Published online: 1 May 2009 
Table 1 Extracted from the Finnish Evidence-Based Guideline for Open-Angle Glaucoma (Tuulonen $e t a l^{6}$ )

\begin{tabular}{|c|c|c|c|c|}
\hline Normal & Abnormal & Diagnosis & Comments & Procedure \\
\hline ONH, VF, NFL & & Normal findings & & \\
\hline VF, NFL & $\mathrm{ONH}$ & Suspected glaucoma & Large optic disc? & \\
\hline $\mathrm{VF}, \mathrm{ONH}$ & NFL & Preperimetric glaucoma? & SWAP may be abnormal & $\begin{array}{l}\text { Follow-up without treatment } \\
\text { (unless IOP }>30 \mathrm{~mm} \mathrm{Hg} \text { ) }\end{array}$ \\
\hline ONH, NFL & VF & Suspected glaucoma & $\begin{array}{l}\text { Repeat examination } \\
\text { Other cause? }\end{array}$ & \\
\hline $\mathrm{ONH}$ & VF, NFL & Glaucoma & Small optic disc? & \\
\hline NFL & $\mathrm{VF}, \mathrm{ONH}$ & $\begin{array}{l}\text { Diagnosis other than glaucoma } \\
\text { (eg, neurological disease) }\end{array}$ & Very rare in glaucoma & $\begin{array}{l}\text { Initiate (or consider initiating) } \\
\text { treatment }\end{array}$ \\
\hline VF & $\begin{array}{l}\text { ONH, NFL } \\
\text { ONH, VF, NFL }\end{array}$ & $\begin{array}{l}\text { Preperimetric glaucoma } \\
\text { Glaucoma }\end{array}$ & SWAP may be abnormal & \\
\hline
\end{tabular}

Abbreviations: $\mathrm{NFL}=$ nerve fiber layer; $\mathrm{ONH}=$ optic nerve head; $\mathrm{VF}=$ visual field.

aimed at providing a uniform diagnosis and treatment of glaucoma by applying evidence-based knowledge to central issues. Therefore, the use of the Finnish Guideline may help to produce effective individual treatment plans for glaucoma patients (Table 1).

Application of the Finnish Evidence-Based Guideline requires evaluation of the $\mathrm{ONH}$ and RNFL, as well as evaluation of the function. Patient classification depends on the tests used for these evaluations. In clinical practice, ONH and RNFL evaluations are carried out using funduscopy or ONH stereophotography and red-free fundus photography. In both cases, subjective evaluation of the images may induce an error in application of the Finnish guideline. The Finnish Evidence-Based Guideline may be applied to findings of the ONH and RNFL obtained using imaging devices; the use of these devices decreases the need for subjective input and may therefore improve the accuracy of the Finnish guideline.

In this study, we compared the performance of Heidelberg retina tomograph (HRT) and scanning laser polarimetry (GDx) with photography for evaluating the ONH and RNFL for application of the Finnish Evidence-Based Guideline for Open-Angle Glaucoma.

\section{Materials and methods}

\section{Participants}

All participants were prospectively enrolled in this study at the Department of Ophthalmology of the Miguel Servet University Hospital (Zaragoza, Spain). Only one eye from each patient was randomly selected for the study.

All participants met the following criteria: best corrected visual acuity of at least 20/30; refractive errors of $<5$ dioptres spherical and 3.00 dioptres of astigmatism; open anterior chamber angle; and transparent ocular media. Written informed consent was obtained from all the participants and the study followed the tenets of the Declaration of Helsinki principles. Exclusion criteria included ocular trauma, surgery, or disease (other than glaucoma); systemic disease with ophthalmic involvement; or inability to perform any procedure of the study.

\section{Procedures}

All participants underwent a full ophthalmic examination, including evaluation by slit-lamp biomicroscopy, measurement of intraocular pressure (IOP), central corneal ultrasonic pachymetry (DGH Technology, model DGH 500), ONH stereophotography, standard automated perimetry (SAP), HRT3, laser polarimetry with variable corneal compensation (GDx-VCC), and optical coherence tomography (OCT). Short wavelength-automated perimetry (SWAP) was also evaluated in patients classified into certain groups, following the recommendations of the Finnish guideline.

\section{Study groups}

Application of the Finnish Evidence-Based Guideline classifies the participants into several groups, such as participants with normal findings, and several groups with suspected glaucoma or glaucoma.

Similar to other studies, ${ }^{7}$ the participants were not selected by applying the gold-standard glaucoma test. The gold-standard glaucoma test for diagnosis is widely accepted as providing an accurate diagnosis and can therefore be used as the standard against which other diagnostic strategies are judged. As glaucoma cannot be defined outside the context of structure and function, and both structure and function were being evaluated in this study, the use of a structural or functional gold standard could induce a bias. Nevertheless, sufficient representation of normal participants and glaucoma 
patients and suspects was ensured by selecting patients from two different sources:

Source 1 (Control group): Hospital staff or participants with refractive problems (eg, near-sightedness or low refractive problems) or patients with problems other than glaucoma that would not interfere with the study (eg, patients seen in the emergency room with irrelevant ocular symptoms). All these participants met the inclusion criteria and an additional inclusion criterion of IOP $<21 \mathrm{~mm} \mathrm{Hg}$.

Source 2 (Study group): Participants referred to us by other ophthalmologists for glaucoma evaluation. Our department is the referral hospital for several ophthalmic outpatient facilities and hospitals that do not have ancillary tests available for glaucoma other than SAP.

\section{Application of the Finnish Evidence-Based Guidelines for Open-Angle Glaucoma in participants from the Control group (Source 1) and the Study group (Source 2)}

The Finnish Evidence-Based Guideline classifies a given participants into one of the eight diagnostic categories (Table 1). In this study, we applied the Finnish guideline on the basis of standard photography (see Application A) or findings from imaging devices (see Application B).

A. Clinical application of the Finnish guideline on the basis of stereophotography

A1. SAP. Perimetries were carried out with a Humphrey Field analyzer 750, using the 24-2 Swedish interactive threshold algorithm standard strategy. Distance correction was added to participant refraction. If fixation losses were $>20 \%$, or false-positive or falsenegative rates were $>33 \%$ (rates of reliability fixed by the perimeter software), the test was repeated. The second reliable perimetry was used for this study to minimize the learning effect. ${ }^{8}$ Consistency of the defects was required; otherwise the perimetries were repeated.

Visual field defects were defined by the deficits that produced a cluster of three or more points that were lower than a $5 \%$ probability level or a cluster of two or more points that were lower than a $1 \%$ probability level, ${ }^{9}$ and/or pattern standard deviation (PSD) with a 5\% probability level or lower, and/or glaucoma hemifield test outside normal limits.

A2. Expert evaluation of $\mathrm{ONH}$ stereophotographic sets. Glaucomatous defects were defined by the presence of diffuse or focal defects in the neuroretinal rim or optic disc hemorrhages. The stereophotographic sets were evaluated by two independent, blinded observers (LP, JML). In case of disagreement, both observers re-evaluated the diagnosis together and reached a consensus.

A3. Expert evaluation of RNFL red-free fundus photography. RNFL photographs were evaluated by two experts on a different day than the optic disc photographs. RNFL defects were defined by the presence of focal or diffuse loss of retinal nerve fiber bundles.

B. Application of the Finnish guideline on the basis of imaging devices:

B1. SAP. Evaluation of the visual field was not a study variable. The same criteria as mentioned above were applied.

B2. ONH evaluation by HRT (parameter glaucoma probability score (GPS)). The HRT3 was carried out in a standardized manner by one examiner. To avoid operator variability in delineating the optic disc rim, GPS was the parameter used in this study. The abnormality criterion was GPS $>0.51$, as proposed in earlier reports. ${ }^{10}$ The optic disc contour was also delineated, however, to obtain data about rim and cup parameters for comparison among groups.

B3. RNFL evaluation by GDx (parameter NFI). The evaluation was carried out with a laser polarimeter GDx-VCC. The diagnostic criterion used for the study was NFI $>30$, as suggested by the manufacturer and earlier studies. ${ }^{7}$

\section{Statistical analysis}

All statistical analyses were calculated using SPSS (version 15.0; SPSS Inc., Chicago, IL, USA) statistical software.

The Kolmogorov Smirnov test was used to check for a normal distribution of the data. Then, differences between both groups were tested using the Students $t$-test.

\section{Results}

A total of 41 control participants (Source 1) and 312 patients (Source 2) were included in the study. The descriptive data of the participants are shown in Table 2.

\section{Diagnostic performance of criteria in the control group (Source 1)}

Although we did not use a gold standard for glaucoma in our study, we expected that in control participants (Source 1) the number of abnormal findings would fall below the expected prevalence of the disease in the general population, particularly in a group of participants with a normal ophthalmic evaluation. As expected, most of the control participants showed no abnormal findings in the tests or after the application of the Finnish Evidence-Based Guideline the percentage of control participants defined as normal by the guideline (specificity) was high (Table 3). 
Table 2 Clinical data of participants included in the study and differences between both sources of participants

\begin{tabular}{|c|c|c|c|c|c|c|c|}
\hline & \multicolumn{3}{|c|}{ Source 1 control group } & \multicolumn{3}{|c|}{ Source 2 study group } & \multirow[t]{2}{*}{ P-value } \\
\hline & $\mathrm{N}$ & Mean & $S D$ & $\mathrm{~N}$ & Mean & $S D$ & \\
\hline Visual acuity & 41 & 0.9 & 0.1 & 312 & 0.9 & 0.1 & 0.77 \\
\hline Age & 41 & 58.0 & 11.2 & 312 & 56.5 & 12.2 & 0.45 \\
\hline IOP $(\mathrm{mm} \mathrm{Hg})$ & 41 & 15.0 & 2.5 & 312 & 23.3 & 3.2 & $<0.001$ \\
\hline Pachymetry $(\mu \mathrm{m})$ & 41 & 552.7 & 33.3 & 312 & 564.0 & 39.6 & 0.05 \\
\hline $\mathrm{C} / \mathrm{D}$ & 41 & 2.8 & 1.6 & 312 & 5.3 & 2.1 & $<0.001$ \\
\hline MD & 41 & -0.9 & 2.4 & 312 & -1.5 & 3.5 & 0.170 \\
\hline PSD & 41 & 1.1 & 1.4 & 312 & 1.8 & 2.4 & 0.001 \\
\hline
\end{tabular}

Abbreviations: $\mathrm{C} / \mathrm{D}=$ cup-to-disc ratio (biomicroscopy); $\mathrm{IOP}=$ intraocular pressure; $\mathrm{MD}=$ mean deviation; $N=$ number of cases; $\mathrm{PSD}=$ pattern standard deviation; $\mathrm{SD}=$ standard deviation.

Table 3 Comparative classification of control participants (Source 1) after the application of the guideline with photographs vs imaging devices (HRT and GDx)

\begin{tabular}{llcr}
\hline Normal findings & $\begin{array}{l}\text { Abnormal } \\
\text { findings }\end{array}$ & $\begin{array}{c}\text { Photographic } \\
\text { evaluation }\end{array}$ & $\begin{array}{r}\text { HRT and } \\
\text { GDx }\end{array}$ \\
\hline VF, NFL, ONH & - & 32 & 34 \\
VF, NFL & ONH & 4 & 2 \\
VF, ONH & NFL & 2 & 1 \\
VF & NFL, ONH & 3 & 1 \\
NFL, ONH & VF & & 3 \\
NFL & VF, ONH & & \\
ONH & VF, NFL & 41 & \\
- & VF, NFL, ONH & $78 \%$ & $83 \%$ \\
& Total & \\
\hline
\end{tabular}

Abbreviations: $\mathrm{GDx}=$ scanning laser polarimetry; $\mathrm{HRT}=$ Heidelberg retina tomograph; $\mathrm{NFL}=$ nerve fiber layer; $\mathrm{ONH}=$ optic nerve head; $\mathrm{VF}=$ visual field

Diagnostic performance of the Finnish Evidence-Based Guideline for open-angle glaucoma in the study group (Source 2)

A comparative distribution of the participants of the study group (Source 2) for the stereophotographic criteria vs the imaging criteria is shown in Table 4 . The Finnish guideline suggests possible sources of error in the different diagnostic groups, for example, large $\mathrm{ONH}$ size. In other cases, a diagnosis of preperimetric glaucoma was confirmed with the SWAP findings, as suggested by the Finnish guideline. In participants that required SWAP evaluation, defects were defined by deficits that produced a cluster of four or more points that were lower than a 5\% probability level or a cluster of three or more points that were lower than a $1 \%$ probability level. ${ }^{11}$

Quantitative data of the ONH and RNFL measured by HRT and GDx are shown in the corresponding tables (photographic evaluation and imaging devices, tables 5 and 6). Also, mean retinal thickness, measured by OCT
(Stratus OCT), is shown to allow comparison of groups tested with an independent device.

\section{Discussion}

This study was designed to test the performance of the Finnish Evidence-Based Guideline for Open-Angle Glaucoma in control participants with no obvious signs of ocular disease (Controls; Source 1) and patients sent to our Glaucoma unit without further discrimination (Subjects; Source 2). Therefore, the difference between groups is on the basis of the origin of the group.

As explained in the Materials and methods, a gold standard for the diagnosis of glaucoma was not used so as to avoid biasing our results by the use of any structural or functional definition of glaucoma. Control participants (Source 1) are a sample extracted from general population, with similar demographic data (Caucasians, age, visual acuity) as the study group without glaucoma findings on routine ophthalmic evaluation. As in the general population, this group may contain glaucoma patients, but the prevalence of such cases is expected to be lower than the prevalence of glaucoma in the general adult population because the routine examination excluded participants with any evident damage in the fundus evaluation. Despite the fact that it is unlikely that there were any glaucoma patients in the control group, these participants should not be considered 'conventional normal participants', but rather as a sample that allows for comparison with a general adult population.

Application of the guideline classified most of control participants as normal individuals (without abnormal findings). Therefore, the diagnostic criteria defined for stereophotographic evaluation of the ONH and RNFL and the imaging devices showed a high specificity, although the strict sense of specificity should be questioned because a gold standard was not used to verify the diagnosis (inherent to the study design). 
Table 4 Comparative classification of participants (from Source 2) on the basis of the findings of photographic evaluation of optic nerve head and nerve fiber layer vs classification on the basis of GPS (HRT) and NFI (GDx-VCC)

\begin{tabular}{|c|c|c|c|c|c|c|c|c|c|c|}
\hline \multirow[b]{2}{*}{ Findings } & \multirow[b]{2}{*}{ Normal } & \multicolumn{9}{|c|}{$V F+G P S(H R T)+N F I(G D x)$} \\
\hline & & $\begin{array}{c}V F \\
N F L O N H\end{array}$ & $\begin{array}{c}V F \\
N F L\end{array}$ & $\begin{array}{c}V F \\
O N H\end{array}$ & $V F$ & $\begin{array}{l}\text { NFL } \\
\text { ONH }\end{array}$ & $N F L$ & $\mathrm{ONH}$ & - & \\
\hline Normal & Abnormal & - & $\mathrm{ONH}$ & $N F L$ & $\begin{array}{l}\text { NFL } \\
\text { ONH }\end{array}$ & $V F$ & $\begin{array}{c}V F \\
\text { ONH }\end{array}$ & $\begin{array}{c}V F \\
N F L\end{array}$ & $\begin{array}{c}V F \\
N F L \\
O N H\end{array}$ & Total \\
\hline \multicolumn{11}{|l|}{$V F+P E$} \\
\hline VF, NFL, ONH & - & 115 & 47 & 8 & 5 & & & & & 175 \\
\hline $\mathrm{VF}, \mathrm{NFL}$ & $\mathrm{ONH}$ & 2 & 2 & & & & & & & 4 \\
\hline $\mathrm{VF}, \mathrm{ONH}$ & NFL & 7 & 8 & & & & & & & 15 \\
\hline VF & $\mathrm{NFL}, \mathrm{ONH}$ & 11 & 27 & & 13 & & & & & 51 \\
\hline $\mathrm{NFL}, \mathrm{ONH}$ & $\mathrm{VF}$ & & & & & 2 & 1 & 2 & & 5 \\
\hline NFL & $\mathrm{VF}, \mathrm{ONH}$ & & & & & & & & & 0 \\
\hline $\mathrm{ONH}$ & $\mathrm{VF}, \mathrm{NFL}$ & & & & & 3 & & & & 3 \\
\hline \multirow[t]{2}{*}{-} & $\mathrm{VF}, \mathrm{NFL}, \mathrm{ONH}$ & & & & & 6 & 17 & 3 & 33 & 59 \\
\hline & Total & 135 & 84 & 8 & 18 & 11 & 18 & 5 & 33 & 312 \\
\hline
\end{tabular}

Abbreviations: GDx = scanning laser polarimetry; GPS = glaucoma probability score; NFI = nerve fiber indicator; $\mathrm{NFL}=$ nerve fiber layer; $\mathrm{ONH}=\mathrm{optic}$ nerve head; $\mathrm{PE}=$ photographic evaluation; $\mathrm{VF}=$ visual field.

Table 5 Finnish Evidence-Based Guideline for Open-Angle Glaucoma implemented by photographic evaluation of optic nerve head and RNFL

\begin{tabular}{|c|c|c|c|c|c|c|c|c|c|c|c|c|c|c|c|c|c|}
\hline \multicolumn{2}{|c|}{ Findings } & \multirow[t]{2}{*}{$\mathrm{n}$} & \multicolumn{2}{|c|}{ Disc } & \multicolumn{2}{|c|}{ Pachymetry } & \multicolumn{2}{|c|}{$M D$} & \multicolumn{2}{|c|}{$P S D$} & \multirow{2}{*}{$\begin{array}{c}\text { Abnormal } \\
\text { SWAP } \\
\mathrm{n}(\%)\end{array}$} & \multicolumn{2}{|c|}{$N F I(G D x)$} & \multicolumn{2}{|c|}{$\begin{array}{c}\text { Avg thick. } \\
\text { (OCT) }\end{array}$} & \multicolumn{2}{|c|}{ FSM (HRT) } \\
\hline Normal & Abnormal & & $x$ & $D E$ & $x$ & $D E$ & $x$ & $D E$ & $x$ & $D E$ & & $x$ & $D E$ & $x$ & $D E$ & $\mathrm{x}$ & $D E$ \\
\hline $\begin{array}{l}\text { VF, NFL, } \\
\text { ONH }\end{array}$ & - & 175 & 2.1 & 0.4 & 572.1 & 36.4 & -0.3 & 1.0 & 1.0 & 0.7 & - & 17.8 & 7.8 & 96.5 & 11.3 & 1.0 & 1.7 \\
\hline VF, NFL & $\mathrm{ONH}$ & 4 & 2.3 & 0.6 & 578.0 & 59.9 & 0.2 & 0.9 & 0.5 & 0.7 & - & 14.3 & 6.8 & 96.3 & 7.2 & -0.4 & 0.7 \\
\hline $\mathrm{VF}, \mathrm{ONH}$ & NFL & 15 & 2.2 & 0.3 & $600.7^{\mathrm{a}}$ & 51.2 & -0.1 & 0.8 & 0.8 & 0.7 & $1(7 \%)$ & 18.7 & 6.1 & 98.5 & 11.5 & 0.7 & 1.2 \\
\hline VF & $\begin{array}{l}\text { NFL, } \\
\text { ONH }\end{array}$ & 51 & $2.4^{\mathrm{a}}$ & 0.5 & 549.6 & 31.5 & -0.6 & 1.4 & 1.1 & 0.7 & $21(41 \%)$ & $24.3^{\mathrm{a}}$ & 11.6 & $85.6^{\mathrm{a}}$ & 19.2 & $-1.2^{\mathrm{a}}$ & 1.8 \\
\hline NFL, ONH & $\mathrm{VF}$ & 5 & 1.5 & 0.2 & 557.8 & 33.7 & -1.0 & 1.3 & 1.6 & 1.9 & - & 24.4 & 12.3 & 81.0 & 10.9 & 1.6 & 1.0 \\
\hline NFL & $\mathrm{VF}, \mathrm{ONH}$ & 0 & 0.0 & 0.0 & 0.0 & 0.0 & 0.0 & 0.0 & 0.0 & 0.0 & - & 0.0 & 0.0 & 0.0 & 0.0 & 0.0 & 0.0 \\
\hline $\mathrm{ONH}$ & VF, NFL & 3 & 1.9 & 0.1 & 558.3 & 28.5 & -2.7 & 2.5 & 3.0 & 0.3 & - & 17.0 & 5.3 & 86.7 & 9.0 & 1.0 & 1.1 \\
\hline- & $\begin{array}{l}\text { VF, NFL, } \\
\text { ONH }\end{array}$ & 59 & 2.2 & 0.4 & 542.6 & 37.7 & $-6.5^{\mathrm{a}}$ & 5.4 & $5.2^{\mathrm{a}}$ & 3.6 & - & $43.6^{a}$ & 22.2 & $70.8^{\mathrm{a}}$ & 13.3 & $-2.6^{\mathrm{a}}$ & 2.4 \\
\hline \multicolumn{2}{|c|}{ Control group } & 41 & 2.0 & 0.3 & 552.7 & 33.3 & -0.9 & 2.4 & 1.1 & 1.4 & - & 14.5 & 8.4 & 101.2 & 10.4 & 1.6 & 1.5 \\
\hline
\end{tabular}

Abbreviations: FSM=Frederick S Mikelberg discriminant function; GDx=scanning laser polarimetry; HRT=Heidelberg retina tomography; $\mathrm{MD}=$ mean deviation; $n=$ number; $\mathrm{NFI}=$ nerve fiber indicator; $\mathrm{NFL}=$ nerve fiber layer; OCT $=$ optical coherence tomography; ONH $=$ optic nerve head; PSD = pattern standard deviation; SWAP = short wavelength-automated perimetry; VF = visual field.

The Table shows the number of participants in each category and the different functional and structural parameters. SWAP was only carried out in the categories recommended by the Finnish guideline.

asignificantly different from controls; bold characters indicate $P<0.05$.

The prevalence of glaucoma in these participants (without obvious signs of ocular disease) is expected to be lower than that of glaucoma in the general population, thus the specificity of the Finnish guideline was at least 78\% (stereophotographic) and 83\% (imaging devices). There were few differences between the two methods. The Finnish guideline on the basis of stereophotographic evaluation did not classify any participant into a category for which treatment is advised, whereas the Finnish guideline on the basis of imaging devices classified 1 of the 41 participants in the category of preperimetric glaucoma. One participant showed abnormal ONH and NFL and normal VF, and was advised to initiate, or consider initiating, treatment. One of the strong points of the use of these guidelines is that it minimizes diagnostic errors on the basis of a single criterion (or gold standard) that may jeopardize the quality of life of a participant because these guidelines require that two of 
Table 6 Finnish Evidence-Based Guideline for Open Angle Glaucoma implemented by imaging devices: HRT (parameter GPS) and GDx (parameter NFI)

\begin{tabular}{|c|c|c|c|c|c|c|c|c|c|c|c|c|c|c|c|c|c|}
\hline \multicolumn{2}{|c|}{ Findings } & \multirow[t]{2}{*}{$\mathrm{n}$} & \multicolumn{2}{|c|}{ Disc } & \multicolumn{2}{|c|}{ Pachymetry } & \multicolumn{2}{|c|}{$M D$} & \multicolumn{2}{|c|}{$P S D$} & \multirow{2}{*}{$\begin{array}{c}\begin{array}{c}\text { Abnormal } \\
\text { SWAP }\end{array} \\
\mathrm{n}(\%)\end{array}$} & \multicolumn{2}{|c|}{$N F I(G D x)$} & \multicolumn{2}{|c|}{$\begin{array}{l}\text { Avg thick. } \\
\text { (OCT) }\end{array}$} & \multicolumn{2}{|c|}{$F S M(H R T)$} \\
\hline Normal & Abnormal & & $X$ & $D E$ & $X$ & $D E$ & $x$ & $D E$ & $\mathrm{x}$ & $D E$ & & $x$ & $D E$ & $\mathrm{x}$ & $D E$ & $x$ & $D E$ \\
\hline $\begin{array}{l}\text { VF, NFL, } \\
\text { ONH }\end{array}$ & - & 135 & 2.0 & 0.4 & 575.2 & 34.2 & -0.4 & 1.0 & 1.0 & 0.7 & - & 16.2 & 6.3 & 98.0 & 10.5 & 1.2 & 1.7 \\
\hline VF, NFL & $\mathrm{ONH}$ & 84 & $2.4^{*}$ & 0.4 & 566.8 & 41.3 & -0.1 & 1.0 & 1.0 & 0.7 & - & 18.2 & 6.0 & 93.1 & 16.3 & $-0.3^{*}$ & 1.6 \\
\hline $\mathrm{VF}, \mathrm{ONH}$ & NFL & 8 & 1.8 & 0.3 & 573.0 & 49.1 & 0.3 & 0.8 & 1.0 & 0.9 & $0(0 \%)$ & $36.4^{*}$ & 4.4 & $81.9^{*}$ & 10.7 & 1.4 & 2.6 \\
\hline VF & $\begin{array}{l}\text { NFL, } \\
\text { ONH }\end{array}$ & 18 & 2.2 & 0.4 & 534.9 & 36.1 & -0.7 & 1.7 & 0.8 & 0.7 & $11(61 \%)$ & $38.3^{*}$ & 8.6 & $78.8^{*}$ & 12.5 & $-1.4^{*}$ & 1.7 \\
\hline $\mathrm{NFL}, \mathrm{ONH}$ & VF & 11 & 1.9 & 0.4 & 565.1 & 45.7 & -3.3 & 3.3 & $4.1^{*}$ & 1.7 & - & 16.9 & 5.1 & 86.9 & 10.5 & 0.4 & 1.0 \\
\hline NFL & $\mathrm{VF}, \mathrm{ONH}$ & 18 & 2.3 & 0.5 & 535.2 & 34.4 & $-5.1^{*}$ & 5.5 & $4.7^{*}$ & 2.9 & - & 23.8 & 4.0 . & $77.2^{*}$ & 12.6 & $-2.5^{*}$ & 3.2 \\
\hline $\mathrm{ONH}$ & VF, NFL & 5 & 2.0 & 0.5 & 560.6 & 40.3 & -1.4 & 1.7 & 1.2 & 1.3 & - & $41.0^{*}$ & 15.4 & $71.4^{*}$ & 5.1 & -0.7 & 2.9 \\
\hline - & $\begin{array}{l}\text { VF, NFL, } \\
\text { ONH }\end{array}$ & 33 & 2.2 & 0.4 & 540.2 & 33.0 & $-7.9^{*}$ & 5.5 & $5.7^{*}$ & 4.2 & - & $58.4^{*}$ & 17.4 & $64.8^{*}$ & 10.4 & $-2.9^{*}$ & 2.0 \\
\hline $\begin{array}{l}\text { Control } \\
\text { group }\end{array}$ & & 41 & 41 & 0.3 & 552.7 & 33.3 & -0.9 & 2.4 & 1.1 & 1.4 & - & 14.5 & 8.4 & 101.2 & 10.4 & 1.6 & 1.5 \\
\hline
\end{tabular}

Abbreviations: FSM=Frederick S Mikelberg discriminant function; GDx=scanning laser polarimetry; HRT=Heidelberg retina tomography; $\mathrm{MD}=$ mean deviation; $n=$ number; $\mathrm{NFI}=$ nerve fiber indicator; $\mathrm{NFL}=$ nerve fiber layer; $\mathrm{OCT}=$ optical coherence tomography; $\mathrm{ONH}=\mathrm{optic}$ nerve head; $\mathrm{PSD}=$ pattern standard deviation; SWAP = short wavelength-automated perimetry; $\mathrm{VF}=$ visual field.

The table shows the number of participants in each category and the different functional and structural parameters. SWAP was only carried out in the categories recommended by the Finnish guideline.

Significant differences from controls $(P<0.05)$ are indicated with asterisks $\left(^{*}\right)$ and bold characters.

the three criteria are met to initiate treatment. Otherwise, participants may have suspected glaucoma, but no treatment is advised. Use of this liberal definition of specificity (on the basis of procedure recommendations, see Table 1) increases the specificity values to 100 and $97.6 \%$, respectively. These results are in general agreement with the specificity reported by the earlier authors for photographic and imaging criteria. ${ }^{12}$

In contrast, the diagnostic performance of the Finnish guideline in the participants from Source 2 produced a high number of positives. Group 2 is not a conventional 'case or glaucoma' group and cannot be considered as the glaucoma group. This group includes both normal participants and glaucoma cases. Normal findings in Source 2 are expected and do not indicate a lack of sensitivity because this group is not a glaucoma group, although the proportion of glaucoma participants in this group can be compared with a clinical setting of a Glaucoma Unit.

The distribution of patients according to application of the Finnish guideline by either method showed certain agreement. The concordance of diagnostic groups was $52.9 \%$ (patients on the diagonal of Table 5), whereas the concordance within a group with similar treatment advice was $56.4 \%$. In every classification group, however, there were several findings that warrant special comment.

The participants (Source 2) with normal findings tended to have thicker corneas than controls (Source 1, $P=0.05$ ). In our opinion, the most interesting finding is that the differences from the control group were greater among participants referred for a glaucoma workup with normal performance in the tests than among study participants with evidence of glaucoma. Although the differences were not significant at the $P<0.05$ level (pachymetry in the control group vs normal findings with imaging devices; $P=0.17$ ), the pachymetry findings of the glaucoma patients and controls were similar $(P=0.85-1.00)$, whereas participants biased by increased IOP may have thicker corneas $(P=0.15)$. If pachymetry findings were a pathogenic factor, elevated pachymetries should be equally distributed in all the categories.

A considerable number of participants was classified as abnormal on ONH (and normal NFL and VF) by imaging, but normal on stereophotographs (47 subjects). In fact, imaging devices classified 84 participants in this category, whereas the photographic evaluation classified only four patients in this category. This fact may be explained by interference because of optic disc size. Participants with abnormal ONH findings, but without abnormal visual field and RNFL findings, had greater optic disc sizes than controls, although the differences were significant only when the Finnish guideline was applied to the results obtained by imaging devices. Thus, optic disc size may interfere with the classification on the basis of GPS, whereas stereophotographic evaluation compensates for this factor.

In contrast, the preperimetric glaucoma group defined by abnormal findings in RNFL and ONH included a high number of participants with abnormal SWAP findings, 
confirming the existence of functional deficits not detected by SAP (41 and $61 \%$ of participants). This preperimetric glaucoma was also confirmed by significant differences in the mean retinal thickness compared with control participants.

A high number of participants matched the preperimetric glaucoma category and therefore it was the most frequent overlapping category between normalcy and glaucoma, with structural deficits detected without functional deficits found in SAP. It was more common to find alterations in both the RNFL and the optic disc than in just the RNFL (in imaging and photographs). This fact might be partially explained by the exclusion of participants without good quality images, as 18 participants were excluded from the study because of low-quality RNFL photographs, and 6 of these 18 subjects also had low-quality ONH stereophotographs.

Abnormal performance in SAP with normal findings in the RNFL and ONH was not common and is most likely an artefact, as there were no significant differences from normalcy in any parameters other than PSD. Also, few patients were classified in this category. The guideline considers these findings to be suspicious of artefacts or other visual field anomalies.

In the case of abnormal findings in the visual field and $\mathrm{ONH}$, suspicion of glaucoma would theoretically increase, but on the basis of the photographic evaluation, none of the participants matched this category. On the other hand, GPS-based criteria included some participants in this category, but GPS tends to overestimate the size of large optic discs, as mentioned earlier. This fact may support the use of RNFL red-free photography because evaluation of the entire bundle of fibers could be more accurate than evaluation with imaging devices of the peripapillary retina. In fact, there are no reports on this type of glaucoma in the literature (6), and the Finnish Guideline for Open-Angle Glaucoma recommends that a diagnosis other than glaucoma be considered (eg, neurologic disease) in such cases.

In conclusion, the Finnish Evidence-Based Guideline for Open-Angle Glaucoma proved to be a useful tool for classifying normal participants and patients with glaucoma or suspected glaucoma through photographic or imaging evaluation. The GPS criterion tended to overestimate the size of large optic discs. In general, structural changes were more frequently detected than functional changes. Although clinical guidelines are useful for glaucoma diagnosis and treatment, clinical decisions should always be made on an individual basis to achieve optimum patient care.

\section{Acknowledgements}

This work has been partially supported by grant FIS PI061382.

\section{References}

1 Van Burkirk EM, Cioffi GA. Glaucomatous optic neuropathy. Am J Ophthalmol 1992; 113: 447-452.

2 Quigley HA, Addicks EM, Green WR. Optic nerve damage in human glaucoma. III Quantitative correlation of nerve fiber loss and visual field defect in glaucoma, ischemic neuropathy, papilledema and toxic neuropathy. Arch Ophthalmol 1982; 100: 135-146.

3 Gaasterland DE, Blackwell B, Dally LG, Caprioli J, Katz LJ, Ederer F, Advanced Glaumoca Intervention Study Investigators (AGIS\#10). Variability among academic glaucoma subspecialist in assessing optic disc notching. Tr Am Ophth Soc 2001; 99: 177-185.

4 European Glaucoma Society. Terminology and Guidelines for Glaucoma, Ed: DOGMA: Savona, Itallia, 2003.

5 American Academy of Ophthalmology. Preferred Practice Pattern: Primary Open-Angle Glaucoma. American Academy of Ophthalmology: San Francisco, 1996.

6 Tuulonen A, Airaksinen PJ, Erola E, Forsman E, Friberq K, Kaila $\mathrm{M}$ et al. The Finnish evidence-based guideline for open-angle glaucoma. Acta Ophthalmol Scand 2003; 81: 3-18.

7 Shah NN, Bowd C, Medeiros FA, Weinreb RN, Sample PA, Hoffmann EM et al. Combining structural and functional testing for glaucoma detection. Ophthalmology 2006; 113: 1593-1602.

8 Heijl A, Lindgren A, Lindgren G. Test-retest variability in glaucomatous visual fields. Am J Ophthalmol 1989; 108: 130-135.

9 Caprioli J. Automated perimetry in glaucoma. Am J Ophthalmol 1991; 111: 235-239.

10 Ferreras A, Pajarín AB, Polo V, Larrosa JM, Pablo L, Honrubia FM. Diagnostic ability of Heidelberg Retina Tomograph classifications for glaucoma: glaucoma probability score $v s$ Moorfields regression analysis. Ophthalmology 2007; 114: 1981-1987.

11 Polo V, Larrosa JM, Pinilla I, Pablo L, Honrubia FM. Optimum criteria for short-wavelength automated perimetry. Ophthalmology 2001; 108: 285-289.

12 Lin SC, Singh K, Jampel HD, Hodapp EA, Smith SD, Francis BA et al. Optic nerve head and retinal nerve fiber layer analysis. Ophthalmology 2007; 114: 1937-1949. 